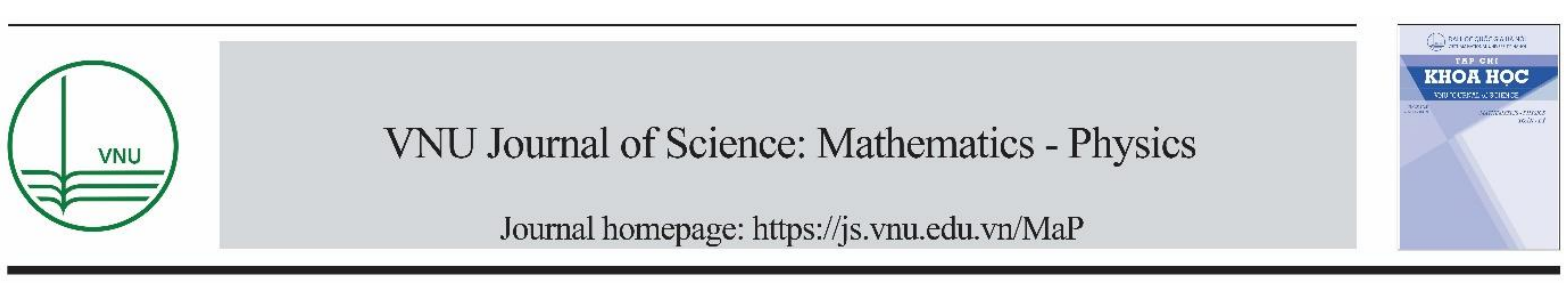

Original Article

\title{
The Role of $\mathrm{Cu}^{2+}$ Concentration in Luminescence Quenching of $\mathrm{Eu}^{3+} / \mathrm{Cu}^{2+} \mathrm{Co}$-doped $\mathrm{ZrO}_{2}$ Nanoparticles
}

\author{
Pham Van Huan ${ }^{1}$, Phuong Dinh Tam ${ }^{1,2}$, Nguyen Thi Ha Hanh ${ }^{3}$, \\ Cao Xuan Thang ${ }^{1}$, Vuong-Hung Pham ${ }^{1, *}$ \\ ${ }^{I}$ Advanced Institute for Science and Technology (AIST), Hanoi University of Science and Technology \\ (HUST), )01 Dai Co Viet, Hanoi, Vietnam \\ ${ }^{2}$ Faculty of Material Science and Engineering, Phenikaa University, Yen Nghia, Hanoi, Vietnam \\ ${ }^{3}$ School of Chemical Engineering, Hanoi University of Science and Technology (HUST), \\ 01 Dai Co Viet, Hanoi, Vietnam
}

Received 25 January 2019

Revised 20 March 2019; Accepted 21 March 2019

\begin{abstract}
This paper the role of $\mathrm{Cu}^{2+}$ concentrations in luminescence quenching of $\mathrm{Eu}^{3+}$ $/ \mathrm{Cu}{ }^{2+}$ doped $\mathrm{ZrO}_{2}$ nanoparticles synthesized by co-precipitation method. The synthesized $\mathrm{Eu}^{3+} / \mathrm{Cu}^{2+}$ doped $\mathrm{ZrO}_{2}$ nanoparticles were observed to have sphere morphology with a diameter of $\sim 25 \mathrm{~nm}$. The XRD patterns of the nanoparticles revealed the peaks that were to be crystalline tetragonal $\mathrm{ZrO}_{2}$. The addition of $\mathrm{Cu}^{2+}$ to the $\mathrm{Eu}^{3+}$ doped $\mathrm{ZrO}_{2}$ nanoparticles resulted in a significant suppress luminescence in $\mathrm{Eu}^{3+} / \mathrm{Cu}^{2+}$ doped $\mathrm{ZrO}_{2}$ nanoparticles, which was attributed to the spectral overlap occurs between $\mathrm{Cu}$ ${ }^{2+}$ absorption and $\mathrm{Eu}^{3+}$ emission $\left({ }^{5} \mathrm{D}_{0} \rightarrow{ }^{7} \mathrm{~F}_{2}\right.$ transition).
\end{abstract}

Keywords: Zirconia; luminescence; precipitation; quenching, nanoparticles.

\section{Introduction}

Zirconia $\left(\mathrm{ZrO}_{2}\right)$ nanoparticles have received considerable attention in optoelectronic materials because of its high refractive index, optical transparency, corrosion resistance, photothermal stability, high thermal expansion coefficient, low thermal conductivity, high thermomechanical resistance, and

\footnotetext{
* Corresponding author.

E-mail address: vuong.phamhung@hust.edu.vn
}

https//doi.org/ 10.25073/2588-1124/vnumap.4320 
catalysis [1,2]. In addition, the stretching energy of $\mathrm{ZrO}_{2}$ is very low that opens up the possibility of higher efficient luminescence of activator ions incorporated into host $\mathrm{ZrO}_{2}$ matrix [3, 4]. While it is generally accepted that doping $\mathrm{Eu}^{3+}$ and $\mathrm{Er}^{3+}$ ions into $\mathrm{ZrO}_{2}$ nanoparticles tailors the luminescence of $\mathrm{ZrO}_{2}$ nanoparticles $[5,6]$. An alternate approach to producing luminescence with tailoring the light emission capabilities is to manipulate the matrix to control energy transfer [7, 8]. Previous studies reported that luminescence quenching for $\mathrm{Eu}^{3+}$ emission was obtained by doping $\mathrm{Cu}^{2+}$ in $\mathrm{ZnO}$ [9] and glass matrix [10]. In particular, in our knowledge, there are no reports on the luminescence quenching for $\mathrm{Eu}^{3+} / \mathrm{Cu}^{2+}$ doped $\mathrm{ZrO}_{2}$ nanoparticles. Therefore, this study proposes a report for suppressing luminescence in $\mathrm{Eu}{ }^{3+}$ emission $\left({ }^{5} \mathrm{D}_{0} \rightarrow{ }^{7} \mathrm{~F}_{2}\right.$ transition) by introducing $\mathrm{Cu}{ }^{2+}$ into $\mathrm{ZrO}_{2}$ matrix. The microstructure and crystal structure of the $\mathrm{Eu}^{3+} / \mathrm{Cu}^{2+}$ doped $\mathrm{ZrO}_{2}$ nanoparticles were characterized by X-ray diffraction (XRD, D8 Advance, Bruker) and field emission scanning electron microscopy (FE-SEM, JEOL, JSM-7600F, JEOL Techniques), respectively. Light emission of nanowire was also determined by photoluminescence spectrometer (NANO LOG spectrofluorometer, Horiba).

\section{Experimental procedure}

$\mathrm{Eu}^{3+} / \mathrm{Cu}^{2+}$ doped $\mathrm{ZrO}_{2}$ nanoparticles were synthesized through a co-precipitation method, as follows: $\mathrm{ZrOCl}_{2} .8 \mathrm{H}_{2} \mathrm{O}$ (99 \% purity, Aldrich, Saint Louis, US), $\mathrm{CuCl}_{2} .2 \mathrm{H}_{2} \mathrm{O}$ (99.9 \%, Aldrich, Saint Louis, Mỹ), and CTAB (99.9 \%, Merck) was dissolved in distilled water (DW) under vigorous stirring at $25^{\circ} \mathrm{C}$ for 30 min to obtain A solution. $\mathrm{Eu}\left(\mathrm{NO}_{3}\right)_{3}$ were obtained by dissolving stoichiometric $\mathrm{Eu}_{2} \mathrm{O}_{3}$ ( $99 \%$ purity, Aldrich) in dilute $\mathrm{HNO}_{3}$ with vigorous stirring. Various amount $(0,1,3,5,7,10$ and 15 $\% \mathrm{~mol} \mathrm{Cu}{ }^{2+}$ ) were used in all the set of the experiments, whereas, the sample was prepared according to the above procedure with the fixed amount of $5 \% \mathrm{~mol} \mathrm{Eu}{ }^{3+}$. The reaction mixture was further stirred for $0.5 \mathrm{~h}$ at $80^{\circ} \mathrm{C}$ and $\mathrm{pH}$ was adjusted to 11 by using aqueous ammonia solution (Duc Giang Chemicals, Hanoi, Vietnam). The resulting precipitates were washed three times and then dried at $600{ }^{\circ} \mathrm{C}$ for $2 \mathrm{~h}$. The crystalline structures of the $\mathrm{Eu}^{3+} / \mathrm{Cu}^{2+}$ doped $\mathrm{ZrO}_{2}$ nanoparticles were characterized by Xray diffraction (XRD, D8 Advance, Bruker, Germany). The microstructure and chemical composition of the $\mathrm{Eu}^{3+} / \mathrm{Cu}^{2+}$ doped $\mathrm{ZrO}_{2}$ nanoparticles were determined by field emission scanning electron microscopy (JEOL, JSM-7600F, JEOL Techniques, Tokyo, Japan) and energy dispersive X-ray spectroscopy (EDS, Gatan, UK). To investigate the absorption properties of $\mathrm{Eu}^{3+} / \mathrm{Cu}^{2+}$ doped $\mathrm{ZrO}_{2}$ nanoparticles, spectra were recorded in the wavelength of 200 to $800 \mathrm{~nm}$ using UV-Vis spectroscopy (Cary 5000, Varian). Photoluminescence (PL) tests were performed to evaluate the optical properties of $\mathrm{Eu}^{3+} / \mathrm{Cu}^{2+}$ doped $\mathrm{ZrO}_{2}$ nanoparticles. NANO LOG spectrofluorometer (Horiba, USA) equipped with $450 \mathrm{~W}$ Xe arc lamp and double excitation monochromators was used. The PL spectra were recorded automatically during the measurements.

\section{Results and discussions}

Figure 1 shows the typical XRD patterns of the $\mathrm{Eu}^{3+} / \mathrm{Cu}^{2+}$ doped $\mathrm{ZrO}_{2}$ nanoparticles synthesized by co-precipitation with different $\mathrm{Cu}^{2+}$ concentrations in the reaction solution. All the $\mathrm{Eu}^{3+} / \mathrm{Cu}^{2+}$ doped $\mathrm{ZrO}_{2}$ nanoparticles showed several strong peaks at $2 \theta=30.2^{\circ}, 35.4^{\circ}, 50.3^{\circ}, 60.2^{\circ}$, and $62.7^{\circ}$ associated with the (001), (200), (112), (121) and (202) plane of the crystalline tetragonal $\mathrm{ZrO}_{2}$ (JCPDS 50-1089, (Fig 1 (b) - (e)). However, the $\mathrm{Eu}^{3+}$ doped $\mathrm{ZrO}_{2}$ nanoparticles synthesized without the addition of $\mathrm{Cu}^{2+}$ showed peaks attributed to the crystalline tetragonal $\mathrm{ZrO}_{2}$ structure (JCPDS (501089 ) with additional peak at $2 \theta \approx 28.4^{\circ}$ corresponded to the $(-111)$ planes of the crystalline monoclonal $\mathrm{ZrO}_{2}$ structure (JCPDS 37-1484), (Fig 1 (a)). These results indicate that the $\mathrm{Eu}^{3+}$ doped 
$\mathrm{ZrO}_{2}$ nanoparticles synthesized with the addition of $\mathrm{Cu}{ }^{2+}$ via a co-precipitation method had the preferential formation of tetragonal phase. It is also can be seen that XRD patterns obtained for all of $\mathrm{Eu}^{3+} / \mathrm{Cu}^{2+}$ doped $\mathrm{ZrO}_{2}$ nanoparticles do not reveal the presence of any phases related to europium and other copper species, suggesting the successful preparation of $\mathrm{Eu}^{3+} / \mathrm{Cu}{ }^{2+}$ doped $\mathrm{ZrO}_{2}$ nanoparticles.

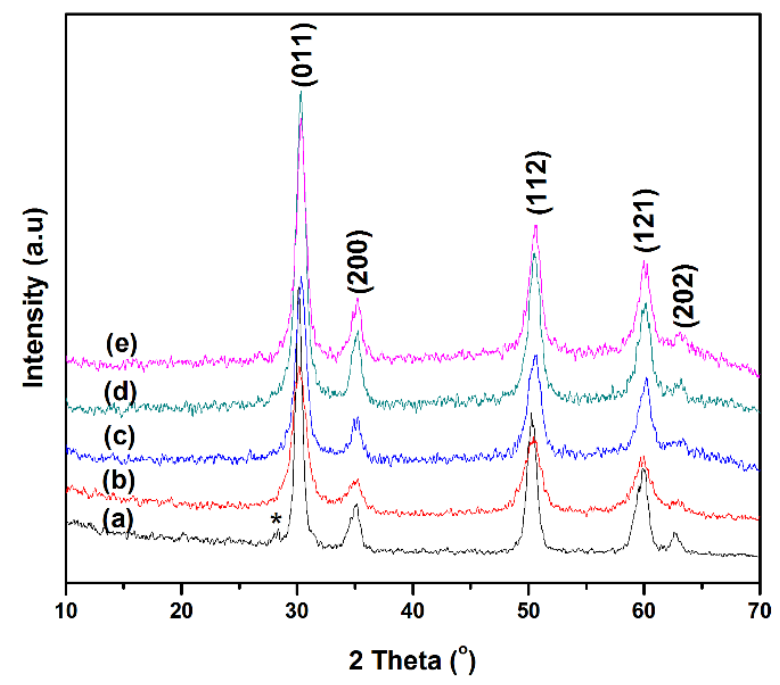

Figure 1. XRD patterns of $\mathrm{Eu}^{3+} / \mathrm{Cu}^{2+}$ doped $\mathrm{ZrO}_{2}$ nanoparticles with different $\mathrm{Cu}^{2+}$ concentrations in the reaction solution. (a) $0 \%$, (b) $1 \%$, (c) $5 \%$, (d) $10 \%$, (e) $15 \% \mathrm{Cu}^{2+}$ in the reaction solution, * monoclonal $\mathrm{ZrO}_{2}$.

The microstructures variation in $\mathrm{Eu}^{3+} / \mathrm{Cu}^{2+}$ doped $\mathrm{ZrO}_{2}$ nanoparticles synthesized coprecipitation method with different concentrations of $\mathrm{Cu}^{2+}$ in the solution was examined by FE-SEM as shown in Figs. 2 (a)-(b). The $\mathrm{Eu}^{3+} / \mathrm{Cu}^{2+}$ doped $\mathrm{ZrO}_{2}$ nanoparticles synthesized with and without $\mathrm{Cu}^{2+}$ dopants showed spheres nanoparticles with the diameter of $\sim 25 \mathrm{~nm}$.
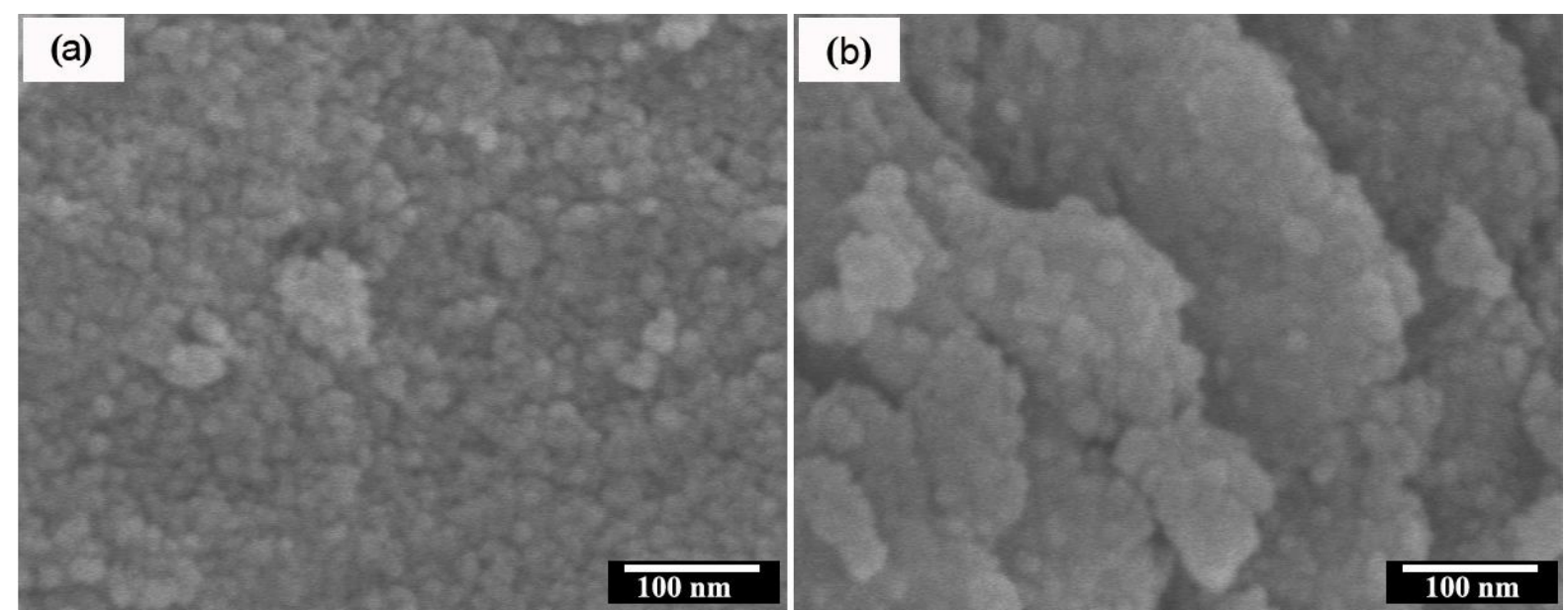

Figure 2. FE-SEM image of $\mathrm{Eu}^{3+} / \mathrm{Cu}^{2+}$ doped $\mathrm{ZrO}_{2}$ nanoparticles synthesized by co-precipitation method with various $\mathrm{Cu}^{2+}$ concentrations in the reaction solution. (a) $15 \% \mathrm{Cu}^{2+}$, (b) $0 \% \mathrm{Cu}^{2+}$ at $100000 \mathrm{X}$ magnification. 
The representative chemical composition of the $\mathrm{Eu}^{3+} / \mathrm{Cu}^{2+}$ doped $\mathrm{ZrO}_{2}$ nanoparticles was characterized by EDS, as shown in Figs. 3. It can be seen that peaks corresponding to the $\mathrm{Cu}$ and $\mathrm{Eu}$ elements were observed, indicating the presence of the $\mathrm{Cu}$ and $\mathrm{Eu}$ in the $\mathrm{ZrO}_{2}$. In addition, a calculated atomic concentration of the $\mathrm{Cu}$ and $\mathrm{Eu}$ incorporated into $\mathrm{ZrO}_{2}$ was $3.6 \%$ and $2.4 \%$, respectively, which would be suggested to the successful doping of $\mathrm{Cu}$ and $\mathrm{Eu}$ into the host $\mathrm{ZrO}_{2}$.

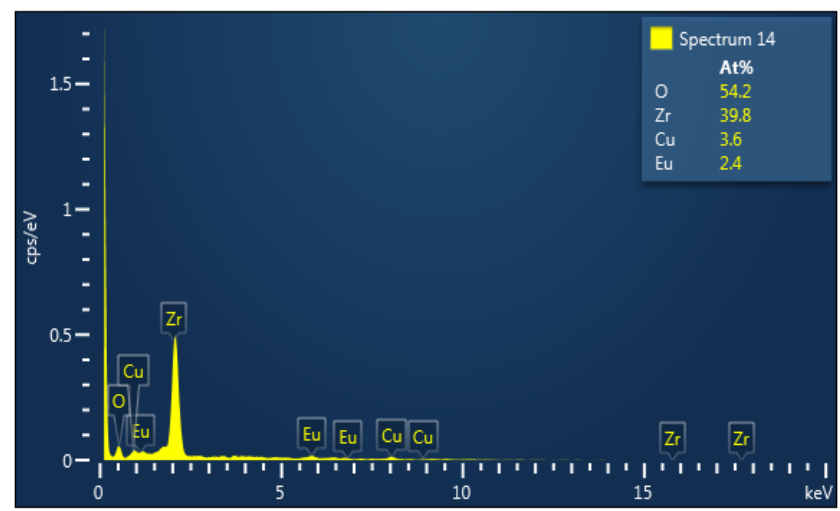

Figure. 3. EDS analysis of chemical composition of $\mathrm{Eu}^{3+} / \mathrm{Cu}^{2+}$ doped $\mathrm{ZrO}_{2}$ nanoparticles prepared by coprecipitation method with $10 \% \mathrm{Cu}^{2+}$ in the reaction solution.

Figure 4 shows the UV-VIS absorption spectrum of $\mathrm{Eu}^{3+} / \mathrm{Cu}{ }^{2+}$ doped $\mathrm{ZrO}_{2}$ nanoparticles synthesized by co-precipitation with different $\mathrm{Cu}^{2+}$ concentrations in the reaction solution $(0-15 \%)$. The $\mathrm{Eu}^{3+} / \mathrm{Cu}^{2+}$ doped $\mathrm{ZrO}_{2}$ nanoparticles synthesized with $0 \% \mathrm{Cu}$ in the reaction solution showed an absorption peak at $\sim 250 \mathrm{~nm}$, Fig. 4 (a). On the other hand, when a certain concentration of $\mathrm{Cu}^{2+}$ was doped, a broad absorption peak at $\sim(250-280) \mathrm{nm}$ was observed attributing for the contributions of $\mathrm{O}^{2-}-\mathrm{Cu}^{2+}$ charge transfer transitions on the $\mathrm{ZrO}_{2}$ with an additional broad peak at $\sim(550 \mathrm{~nm}-800$ $\mathrm{nm}$ ) was assigned to the ${ }^{2} \mathrm{E} \rightarrow{ }^{2} \mathrm{~T}_{2}(\mathrm{~d}-\mathrm{d})$ transition of $\mathrm{Cu}^{2+}$, Fig. 4 (b) - (f) $[11,12]$.

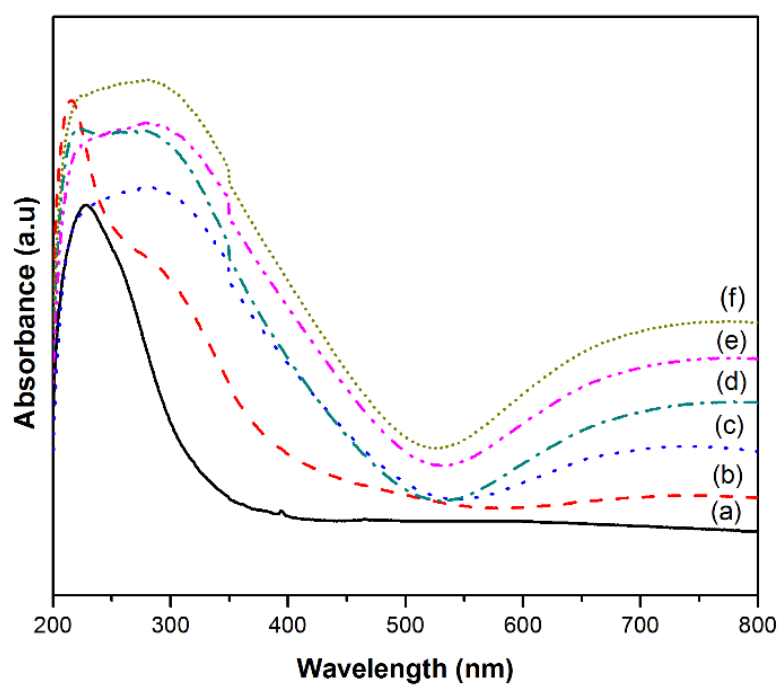

Figure 4. UV-VIS spectra of $\mathrm{Eu}^{3+} / \mathrm{Cu}^{2+}$ doped $\mathrm{ZrO}_{2}$ nanoparticles with various $\mathrm{Cu}^{2+}$ concentrations in the reaction solution. (a) $0 \%$, (b) $1 \%$, (c) $5 \%$, (d) $7 \%$, (e) $10 \%$, (f) $15 \% \mathrm{Cu}^{2+}$. 
Figure 5 shows the emission spectra of $\mathrm{Eu}^{3+} / \mathrm{Cu}^{2+}$ doped $\mathrm{ZrO}_{2}$ nanoparticles with different $\mathrm{Cu}^{2+}$ concentrations in the reaction solution. All the $\mathrm{Eu}^{3+} / \mathrm{Cu}^{2+}$ doped $\mathrm{ZrO}_{2}$ nanoparticles showed strong visible emission peaks appeared at about 590, 616, 650 and $700 \mathrm{~nm}$ and they can be attributed to the ${ }^{5} \mathrm{D}_{\mathrm{o}}-{ }^{7} \mathrm{~F}_{1},{ }^{5} \mathrm{D}_{\mathrm{o}}-{ }^{7} \mathrm{~F}_{2},{ }^{5} \mathrm{D}_{\mathrm{o}}-{ }^{7} \mathrm{~F}_{3},{ }^{5} \mathrm{D}_{0}-{ }^{7} \mathrm{~F}_{4}$ transitions within $\mathrm{Eu}^{3+}$ ion, respectively. However, it should be noted that the PL spectra of the $\mathrm{Eu}^{3+} / \mathrm{Cu}^{2+}$ doped $\mathrm{ZrO}_{2}$ nanoparticles decreased with increasing $\mathrm{Cu}^{2+}$ concentrations. In particular, when the concentration of $\mathrm{Cu}^{2+}$ reach $10 \%$, they reached the significant decreasing the PL intensities and then decreased completely with further increasing $\mathrm{Cu}^{2+}$ concentrations to $15 \%$. This significant decreasing PL was mainly attributed to the achievement of $\mathrm{Cu}$ ${ }^{2+}$ dopants in the $\mathrm{Eu}^{3+} / \mathrm{ZrO}_{2}$ nanoparticles, which can be explained by considering the photo quenching effect. More specifically, a decreasing luminescent emission of $\mathrm{Eu}^{3+} / \mathrm{Cu}{ }^{2+}$ doped $\mathrm{ZrO}_{2}$ nanoparticles is due to the spectral overlap occurring between $\mathrm{Cu}{ }^{2+}$ absorption and $\mathrm{Eu}^{3+}$ emission $\left({ }^{5} \mathrm{D}_{0} \rightarrow{ }^{7} \mathrm{~F}_{2}\right.$ transition) $[10,13]$.

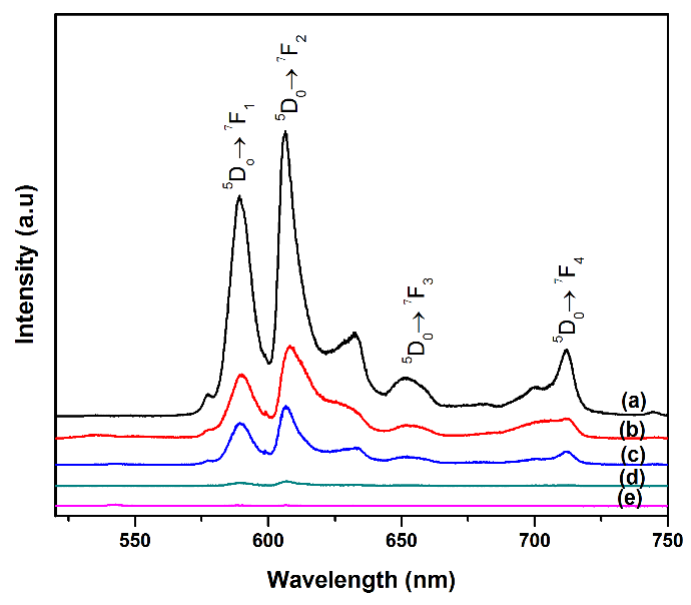

Figure 5. Luminescence spectra of $\mathrm{Eu}^{3+} / \mathrm{Cu}^{2+}$ doped $\mathrm{ZrO}_{2}$ nanoparticles with various $\mathrm{Cu}^{2+}$ concentrations in the reaction solution. (a) $1 \%$, (b) $5 \%$, (c) $7 \%$, (d) $10 \%$, (e) $15 \% \mathrm{Cu}^{2+}$.

\section{Conclusions}

We herein demonstrated that the luminescence quenching of $\mathrm{Eu}^{3+} / \mathrm{Cu}{ }^{2+}$ doped $\mathrm{ZrO}_{2}$ nanoparticles could be obtained effectively by controlling the concentrations of $\mathrm{Cu}^{2+}$ dopants. In particular, the co-doped of $\mathrm{Eu}^{3+}$ and $\mathrm{Cu}^{2+}$ into $\mathrm{ZrO}_{2}$ allows to achieve the tetragonal phase of $\mathrm{ZrO}_{2}$. The $\mathrm{Eu}^{3+} / \mathrm{Cu}^{2+}$ doped $\mathrm{ZrO}_{2}$ nanoparticles synthesized without $\mathrm{Cu}^{2+}$ dopants showed typically visible emission peaks of $\mathrm{Eu}^{3+}$. On the other hand, when a certain concentration of $\mathrm{Cu}{ }^{2+}$ was doped, luminescence quenching $\mathrm{Eu}^{3+} / \mathrm{Cu}^{2+}$ doped $\mathrm{ZrO}_{2}$ nanoparticles was achieved. This luminescence quenching of $\mathrm{Eu}^{3+} / \mathrm{Cu}^{2+}$ doped $\mathrm{ZrO}_{2}$ nanoparticles was mainly attributed to the containing of $\mathrm{Cu}^{2+}$ in the nanoparticle which is a suppressing $\mathrm{Eu}^{3+}$ luminescence.

\section{Acknowledgements}

This research is funded by the Vietnam National Foundation for Science and Technology Development (NAFOSTED) under grant number 103.03-2017. 35. 


\section{References}

[1] R.H. French, S.J. Glass, F.S. Ohuchi, Y.N. Xu, W.Y. Ching, Experimental and theoretical determination of the electronic structure and optical properties of three phases of $\mathrm{ZrO}_{2}$, Physical Review B. 49 (1994) 5133-5142.

[2] S.M. Chang, R.A. Doong, Chemical-composition-dependent metastability of tetragonal $\mathrm{ZrO}_{2}$ in sol-gel-derived films under different calcination conditions, Chem. Mater.17 (2005) 4837-4844.

[3] E. De la Rosa, L.A. Diaz-Torres, P. Salas, R.A. Rodríguez, Visible light emission under UV and IR excitation of rare earth doped $\mathrm{ZrO}_{2}$ nanophosphor, Optical Materials 27 ( 2005) 1320-1325.

[4] I.A.A. Terra, L.J. Borrero-Gonzalez, J.M. Carvalho, M.C. Terrile, M.C.F.C. Felinto, H.F. Brito, L.A.O. Nunes, Spectroscopic properties and quantum cutting in $\mathrm{Tb}^{3+}-\mathrm{Yb}^{3+}$ co-doped $\mathrm{ZrO}_{2}$ nanocrystals, J. Appl. Phys.113 ( 2013) 073105-07311.

[5] M.R.N. Soares, C. Nico, D. Oliveira, M. Peres, L. Rino, A.J.S. Fernandes, T. Monteiro, F.M. Costa, Red light from $\mathrm{ZrO}_{2}$ : Eu ${ }^{3+}$ nanostructures, Materials Science and Engineering B 177 (2012) 712-716.

[6] T. Lãpez-Luke, E. De la Rosa, P. Salas, C. Angeles-Chavez, L.A. Díaz-Torres, S. Bribiesca, Enhancing the upConversion emission of $\mathrm{ZrO}_{2}$ : $\mathrm{Er}^{3+}$ Nanocrystals prepared by a micelle process, J. Phys. Chem. C. 111(2007) 17110-17117.

[7] R.Gunawidjaja, T. Myint, H. Eilers, Temperature-Dependent Phase Changes in Multicolored $\operatorname{Er}_{x} \mathrm{Yb}_{y} \mathrm{Zr}_{1-x-}$ ${ }_{y} \mathrm{O}_{2} / \mathrm{Eu}_{0.02} \mathrm{Y}_{1.98} \mathrm{O}_{3}$ Core/Shell Nanoparticles, J. Phys.Chem C. 117( 2013) 14427-14434.

[8] P.A. Primus, A. Menski, M.P. Yeste, M.A. Cauqui, M.U. Kumke, Fluorescence line-narrowing spectroscopy as a tool to monitor phase transitions and phase separation inefficient nanocrystalline $\mathrm{Ce}_{\mathrm{x}} \mathrm{Zr}_{1-\mathrm{x}} \mathrm{O}_{2}: \mathrm{Eu}^{3+}$ catalyst materials, J. Phys. Chem. C., 119 (2015) 10682-1069.

[9] S. Lãpez-Romero, M.J. Quiroz Jiménez, M. García-Hipãlito, Quenching photoluminescence of Eu (III) by Cu (II) in $\mathrm{ZnO}: \mathrm{Eu}^{3+}+\mathrm{Cu}^{2+}$ compounds by solution Combustion Method, World Journal of Condensed Matter Physics. 6 (2016) 269-275.

[10] J.A. Jiménez, Photoluminescence of $\mathrm{Eu}^{3+}$ Doped Glasses with $\mathrm{Cu}^{2+}$ Impurities, Spectrochimica Acta Part A: Molecular and Biomolecular Spectroscopy 145 (2015) 482-486.

[11] T. Murata, K. Morinaga, Effect of antimony oxide on the deposition and dispersion of metallic copper nanoparticles in phosphate glasses for optical nonlinear materials, Proceedings of the SPIE. 4102 (2000) 316-323.

[12] J.A. Jiménez, Efficient stabilization of $\mathrm{Cu}^{+}$ions in phosphate glasses via reduction of $\mathrm{Cu}^{2+}$ by $\mathrm{Sn}^{2+} \mathrm{during}$ ambient atmosphere melting, J. Mater. Sci. 49 (2014) 4387-4393.

[13] I.M. Batyaev, A.M. Tinus, Transport of electronic excitation energy in solid-state glassy phosphors activated with europium (III) and copper (II), Tech. Phys. Lett. 24 (1998) 26-27. 